\title{
Mumps-virus-associated Clinically Mild Encephalopathy With a Reversible Splenial Lesion
}

\author{
Kaori Kimura ${ }^{a}$, Tatsuo Fuchigamia, d, Wakako Ishii ${ }^{a}$, Yuki Imai ${ }^{a}$, Satomi Tanabe ${ }^{a}$, \\ Remi Kuwabara $^{\text {a }}$, Yukihiko Fujita ${ }^{\mathrm{b}}$, Hideo Mugishima ${ }^{\mathrm{a}}$, Katsuo Aoki ${ }^{\mathrm{c}}$
}

\begin{abstract}
Mumps virus infection primarily involves the parotid glands and most frequently affects young children during the winter and spring months. It is known that mumps virus infection may be accompanied by neurological manifestations, including meningitis and encephalitis. However, few cases of acute encephalopathy have been reported to date. We report a case of a 4-year-old girl with clinically mild encephalopathy with a reversible splenial lesion associated with mumps virus infection. She had swelling of the bilateral parotid glands. She was admitted to our hospital because of reduced level of consciousness, seizures, and vomiting. Cell counts in the cerebrospinal fluid (CSF) were normal. She had a low serum sodium level on admission. Brain computed tomography showed mild cerebral edema. Electroencephalography showed partial highvoltage slow waves at the occipital lesion, and diffusion-weighted magnetic resonance imaging demonstrated a transient abnormality in the splenium of the corpus callosum. We diagnosed clinically mild encephalopathy with a reversible splenial lesion associated with mumps virus infection. She recovered well, and exhibited no neurological sequelae. Mumps virus RNA was not detected in the CSF, suggesting that the reversible splenial change was caused by indirect effects on the central nervous system subsequent to viral infection. Her low serum sodium level also indicates that this change can occur with hyponatremia.
\end{abstract}

Keywords: Corpus callosum; Diffusion-weighted imaging; Encephalopathy; Mumps virus; Splenial lesion

Manuscript accepted for publication October 3, 2012

${ }^{a}$ Department of Pediatrics and Child Health, Nihon University School of Medicine, Tokyo 173-8610, Japan

${ }^{b}$ Division of Medical Education Planning, Nihon University School of Medicine, Tokyo 173-8610, Japan

${ }^{c}$ Division of Pediatrics, IMS Memorial Hospital, Tokyo 174-0071, Japan

${ }^{\mathrm{d}}$ Corresponding author: Tatsuo Fuchigami, Department of Pediatrics and Child Health, Nihon University School of Medicine, 30-1

Oyaguchi-Kamicho, Itabashi-ku, Tokyo 173-8610, Japan.

Email: fuchigami.tatsuo@nihon-u.ac.jp

doi: http://dx.doi.org/10.4021/ijcp51w

\section{Introduction}

Mumps is a common childhood infection caused by the mumps virus. The hallmark of infection is swelling of the parotid gland. Aseptic meningitis and encephalitis are common complications of mumps, together with orchitis and oophoritis, which can arise in adult men and women, respectively; other complications include deafness and pancreatitis [1]. In 2004, Tada et al [2] identified clinically mild encephalitis/ encephalopathy with a reversible splenial lesion (MERS) as a new type of acute encephalopathy, characterized by transient splenial lesions with high-signal intensity on diffusionweighted magnetic resonance imaging (MRI), a mild clinical course, and a good outcome. MERS has been associated with various infectious diseases. Influenza virus A and B are the most common pathogens, following by mumps virus, adenovirus, rotavirus, streptococci, and Escherichia coli in Japan [3]. Although there are some reports of MERS associated with mumps virus infection [2,4], these three cases were all meningoencephalitis and showed pleocytosis with a reversible splenial lesion. The mechanisms of mumps-virusassociated MERS remain unclear.

We report a patient with mumps-virus-associated encephalopathy (without pleocytosis) with a reversible splenial lesion with high-signal intensity on diffusion-weighted MRI. Serum sodium level and the result of viral RNA testing of cerebrospinal fluid (CSF) samples are discussed to elucidate the possible mechanisms of MERS.

\section{Case Report}

A previously healthy 4-year-old girl experienced fever (38.8 ${ }^{\circ} \mathrm{C}$ ) with swelling of the left side parotid glands for 1 day before hospitalization. She visited a general hospital, and was diagnosed with mumps. The following day, she developed swelling of the bilateral parotid glands, and had headache and recurrent vomiting. She visited the previous hospital again and was admitted in the evening. She had neck stiffness. A lumbar puncture was taken, with suspected diagnosis of mumps meningitis. However, her CSF revealed no in- 

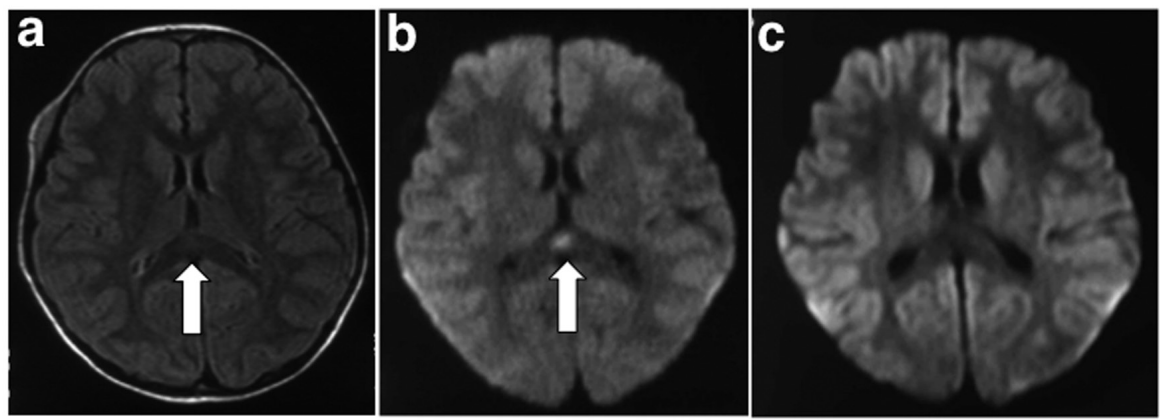

Figure 1. Brain magnetic resonance imaging. a: Fluid-attenuated inversion recovery image on the second day of admission (third day from onset) showed a slightly hyperintense lesion in the splenium of the corpus callosum (arrow); b: Diffusion-weighted image on the second day of admission (third day from onset) showing a focal high-intensity lesion in the splenium of the corpus callosum (arrow); c: Diffusionweighted image on eighth day of admission (ninth day from onset) showing complete resolution of the lesion.

creased cell count. She had generalized tonic seizures lasting about 3 min at night. She was transferred to the Department of Pediatrics, Nihon University School of Medicine Itabashi Hospital, Tokyo, Japan. She was then admitted to our hospital on the second day from onset. Her developmental history was normal, and she had no seizures. She had no history of mumps infection and had not received mumps vaccination.

On admission, she had a temperature of $39.8^{\circ} \mathrm{C}$, heart rate of 148 beats/min, blood pressure of 101/67 $\mathrm{mmHg}$, and respiratory rate of $20 \mathrm{breaths} / \mathrm{min}$. She had delirium with a Glasgow Coma Scale score of E4 V4 M6. Neurological examination showed no abnormality except for her reduced level of consciousness. She had swelling of the bilateral parotid and submandibular glands. She had a positive Kernig's sign as well as nuchal rigidity. Her chest and abdomen showed no abnormal findings.

Laboratory blood testing showed a leukocyte count of $5,600 / \mu \mathrm{L}$, hemoglobin $15.0 \mathrm{~g} / \mathrm{dl}$, platelet count $131,000 / \mu \mathrm{L}$, serum $\mathrm{Na} 131 \mathrm{mEq} / \mathrm{L}, \mathrm{K} 4.5 \mathrm{mEq} / \mathrm{L}, \mathrm{Cl} 93 \mathrm{mEq} / \mathrm{L}$, blood urea nitrogen $16.1 \mathrm{mg} / \mathrm{dL}$, creatinine $0.58 \mathrm{mg} / \mathrm{dL}$, aspartate aminotransferase $51 \mathrm{U} / \mathrm{L}$, alanine aminotransferase $16 \mathrm{U} / \mathrm{L}$, lactate dehydrogenase $307 \mathrm{U} / \mathrm{L}$, creatine kinase $91 \mathrm{U} / \mathrm{L}$, amylase $1266 \mathrm{U} / \mathrm{L}$, glucose $124 \mathrm{mg} / \mathrm{dL}$, and C-reactive protein $3.14 \mathrm{mg} / \mathrm{dL}$. The laboratory data demonstrated a decrease

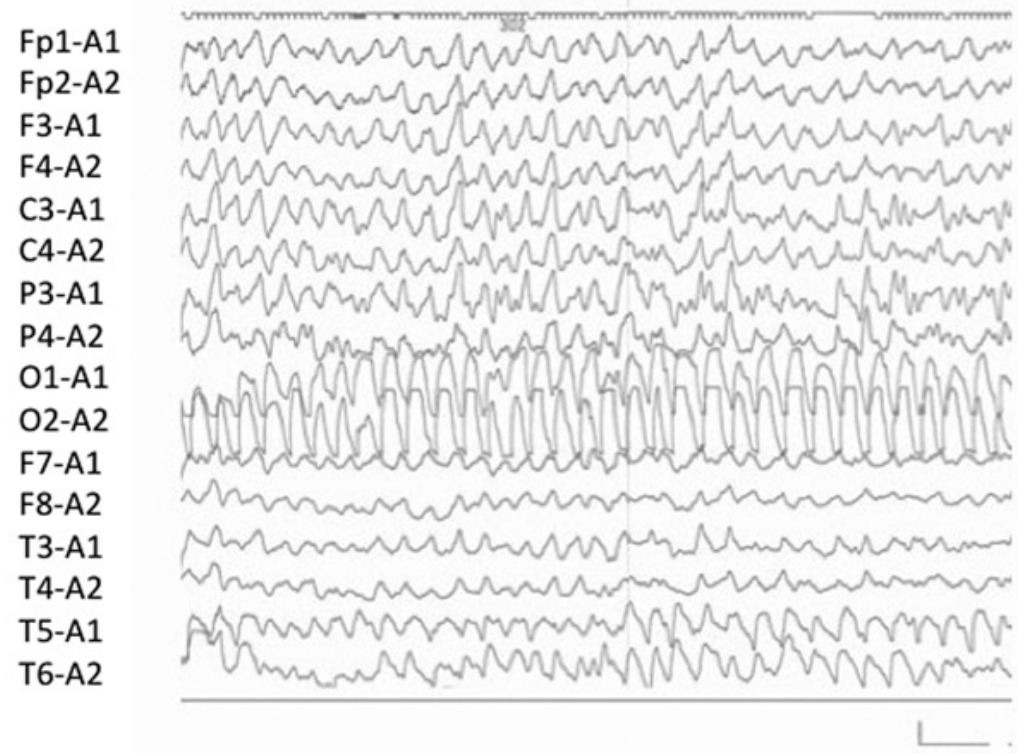

Figure 2. EEG in awake patient (third day from onset) showing a global diffuse, high-voltage, slow wave about $3-4 \mathrm{~Hz}$ in the particularly marked occipital area. Calibration: $100 \mu \mathrm{V}, 1 \mathrm{~s}$. 


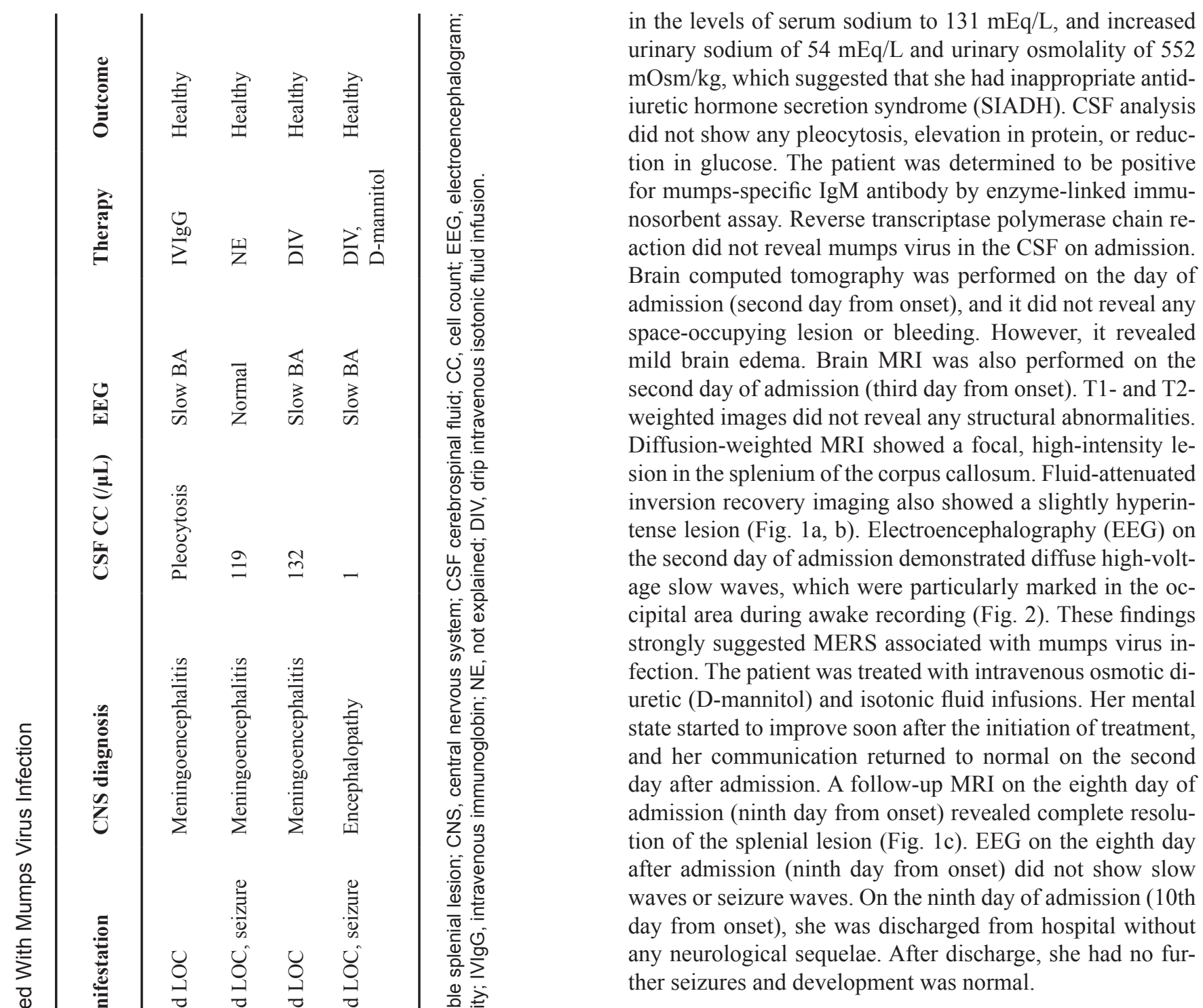

\section{Discussion}

Acute encephalitis is a well-known complication of mumps virus infection; however, few cases of acute encephalopathy have been reported to date [5]. Recently, a total of 983 cases reportedly had acute encephalopathy during 2007 2010 in Japan [6]. Among the pathogens of the preceding infection, influenza virus was the most common $(26 \%)$, followed by human herpesvirus (HHV)-6 (17\%), rotavirus $(4.0 \%)$, respiratory syncytial virus $(1.7 \%)$, and mumps virus $(0.9 \%)$. Among syndromes of acute encephalopathy, acute encephalopathy with biphasic seizures and late reduced diffusion $(28.7 \%)$ was the most frequent, followed by MERS (15.6\%), acute necrotizing encephalopathy (4.0\%). In 153 cases with MERS, pathogens of the preceding infection were influenza virus $(34.4 \%)$, rotavirus (11.7\%), mumps virus $(3.9 \%)$, HHV-6 (2.0\%), and bacterial (3.3\%) infections. 
These results showed that cases of mumps-virus-associated acute encephalopathy and MERS were rare [3, 5, 6]. Three pediatric patients with MERS associated with mumps virus infection have previously been reported $[2,4]$. These cases were all with meningoencephalitis, and no encephalopathy. However, our case of mumps-associated MERS was with encephalopathy and revealed no increased cell count in CSF. The outcome was excellent in all cases with mumps-associated MERS, including our present case (Table 1). Hara et al have reported a case of MERS after mumps vaccination, and this case was also with encephalitis, as revealed by an increased cell count of $624 / \mathrm{mm}^{3}$ in CSF [7]. The sequence of mumps virus obtained from the patient was identical to that of the vaccine strain. This implies that the vaccine strain was strongly associated with MERS in that case. Nine patients with mumps-virus-associated encephalopathy have been reported in Japan in the past 20 years [5]. Although the prognosis in all cases with mumps-virus-associated MERS was excellent, all patients with mumps-virus-associated encephalopathy experienced progressive coma and/or seizures, and their prognoses varied from having no sequelae to death.

Although several viruses have been associated with MERS, the pathophysiological mechanisms remain unclear. We previously have examined the CSF of six patients with seizures associated with rotavirus infection, and detected viral genes in all of the samples [8]. However, rotavirus antigen and RNA have not been detected in the CSF of patients with rotavirus-associated MERS, including our present case [912]. These findings suggest that rotavirus-associated MERS is not caused by direct invasion, but by indirect effects on the central nervous system. However, CSF testing for rotavirus antigen and RNA has not been undertaken in enough cases for this to be definitively concluded.

It has been proposed that MERS may be caused by intramyelinic axonal edema or local inflammatory cell infiltration [2]. Previous studies have reported a close relationship between MERS and hyponatremia involving SIADH. Takanashi et al [13] have reported that most patients with MERS had mild hyponatremia. Hypotonic hyponatremia results in entry of water into the brain, resulting in cerebral edema, headache, nausea, vomiting, confusion, and seizures. It is clinically difficult to separate MERS from hyponatremic encephalopathy, or to rule out hyponatremia as a contributing factor to MERS. Our patient had also a low serum sodium level ( $\mathrm{Na} 131 \mathrm{mEq} / \mathrm{L})$ on admission, and had similar symptoms, such as nausea, vomiting, confusion, and seizure. This finding also indicates that mumps-virus-associated MERS can develop with hyponatremia.

Virus-associated acute encephalopathy is believed to be related to the cytokine storm of varying degrees [14]. There have been several previous reports of elevated interleukin (IL)-6 and soluble tumor necrosis factor receptor-1 levels in the CSF in cases of acute encephalopathy associated with influenza virus [15] and mumps virus [5] infection. IL-6 and nitric oxide metabolites (nitrites and nitrates) have been suggested as potential contributing factors to MERS. IL-6 level was measured in the CSF of a previously reported case of rotavirus-associated MERS, and was found to be extremely high at $952.0 \mathrm{pg} / \mathrm{mL}$ (normal 6-71 pg/mL) [11]. Such a high level of IL-6 suggests significant inflammation of the central nervous system, which may result in an increase in vascular permeability, with or without direct virus invasion. We did not measure IL-6 and nitric oxide metabolite levels in this case.

The present case supports the theory that mumps-virusassociated MERS is not caused by direct viral invasion of the central nervous system. Our patient had a low serum sodium level, indicating that mumps-virus-associated MERS can develop with hyponatremia. IL-6 and nitric oxide metabolites may also contribute to the development of this condition. Further research is required to evaluate this possibility, and improve our understanding of the mechanisms by which mumps virus infection causes neurological sequelae, including mumps-virus-associated MERS.

\section{Informed Consent}

Informed written consent for publication of this case was obtained from the patient's parents.

\section{Conflict of Interest}

The authors declare no potential conflicts of interests with respect to the authorship and/or publication of this article.

\section{Funding}

The authors received no financial support for the research and/or authorship of this article.

\section{References}

1. Hviid A, Rubin S, Muhlemann K. Mumps. Lancet. 2008;371(9616):932-944.

2. Tada H, Takanashi J, Barkovich AJ, Oba H, Maeda M, Tsukahara H, Suzuki M, et al. Clinically mild encephalitis/encephalopathy with a reversible splenial lesion. Neurology. 2004;63(10):1854-1858.

3. Takanashi J. Two newly proposed infectious encephalitis/ encephalopathy syndromes. Brain Dev. 2009;31(7):521528.

4. Matsumoto N, Narahara K, Kiguchi T, Kobatake C, Yamaguchi I, Kawata J, Ando Y, et al. Reversible splenial lesion of the corpus callosum in a patient with mumps meningoencephalitis [in Jananese with Eng- 
lish abstract]. J Jpn Pediatr Soc. 2009; 113(11): 17171720 .

5. Watanabe M, Suyama K, Hashimoto K, Sato M, Ohara S, Abe Y, Kawasaki Y, et al. Mumps VirusAssociated Acute Encephalopathy: Case Report and Review of the Literature. J Child Neurol. 2012. DOI: 10.1177/0883073812441060.

6. Hoshino A, Saitoh M, Oka A, Okumura A, Kubota M, Saito Y, Takanashi J, et al. Epidemiology of acute encephalopathy in Japan, with emphasis on the association of viruses and syndromes. Brain Dev. 2012;34(5):337343.

7. Hara M, Mizuochi T, Kawano G, Koike T, Shibuya I, Ohya T, Ohbu K, et al. A case of clinically mild encephalitis with a reversible splenial lesion (MERS) after mumps vaccination. Brain Dev. 2011;33(10):842-844.

8. Liu B, Fujita Y, Arakawa C, Kohira R, Fuchigami T, Mugishima H, Kuzuya M. Detection of rotavirus RNA and antigens in serum and cerebrospinal fluid samples from diarrheic children with seizures. Jpn J Infect Dis. 2009;62(4):279-283.

9. Fukuda S, Kishi K, Yasuda K, Sejima H, Yamaguchi S. Rotavirus-associated encephalopathy with a reversible splenial lesion. Pediatr Neurol. 2009;40(2):131-133.

10. Arakawa C, Fujita Y, Imai Y, Ishii W, Kohira R, Fuchigami T, Mugishima $\mathrm{H}$, et al. Detection of group a ro- tavirus RNA and antigens in serum and cerebrospinal fluid from two children with clinically mild encephalopathy with a reversible splenial lesion. Jpn J Infect Dis. 2011;64(3):204-207.

11. Mori T, Morii M, Kuroiwa Y, Hotsubo T, Fuse S, Tsustumi H. Rotavirus encephalitis and cerebellitis with reversible magnetic resonance signal changes. Pediatr Int. 2011;53(2):252-255.

12. Fuchigami T, Goto K, Hasegawa M, Saito K, Kida T, Hashimoto K, Fujita Y, et al. A 4-year-old girl with clinically mild encephalopathy with a reversible splenial lesion associated with rotavirus infection. J Infect Chemother. 2012. DOI: 10.1007/s10156-012-0421-8.

13. Takanashi J, Tada H, Maeda M, Suzuki M, Terada H, Barkovich AJ. Encephalopathy with a reversible splenial lesion is associated with hyponatremia. Brain Dev. 2009;31(3):217-220.

14. Mizuguchi M, Yamanouchi H, Ichiyama T, Shiomi M. Acute encephalopathy associated with influenza and other viral infections. Acta Neurol Scand Suppl. 2007;186: 45-56.

15. Ichiyama T, Morishima T, Isumi H, Matsufuji H, Matsubara T, Furukawa S. Analysis of cytokine levels and NF-kappaB activation in peripheral blood mononuclear cells in influenza virus-associated encephalopathy. Cytokine. $2004 ; 27(1): 31-37$. 